\title{
Soil Water Repellency: A Potential Driver of Vegetation Dynamics in Coastal Dunes
}

\author{
Koen Siteur, ${ }^{1 *}$ Jiefei Mao, ${ }^{1,2}$ Klaas G. J. Nierop, ${ }^{2}$ Max Rietkerk, ${ }^{1}$ \\ Stefan C. Dekker, ${ }^{1}$ and Maarten B. Eppinga ${ }^{1}$
}

\begin{abstract}
${ }^{1}$ Copernicus Institute of Sustainable Development - Environmental Sciences, Faculty of Geosciences, Utrecht University, Heidelberglaan 2, P.O. Box 80115, 3508 TC Utrecht, The Netherlands; ${ }^{2}$ Department of Earth Sciences - Organic Geochemistry, Faculty of Geosciences, Utrecht University, Heidelberglaan 2, P.O. Box 80115, 3508 TC Utrecht, The Netherlands
\end{abstract}

\begin{abstract}
Coastal dunes are valuable and complex ecosystems, meaning that predicting their response to anthropogenic pressure is challenging. A potential driver of complexity that links soil, water, and vegetation dynamics is soil water repellency (SWR). SWR is mainly caused by plant-derived hydrophobic compounds that are released during litter decomposition and leads to dry sandy soils resisting infiltration of precipitation. Until now, studies have focused on soil physical and chemical properties associated with SWR, but the potential of SWR generating soil watervegetation feedbacks that drive ecosystem dynamics is yet to be assessed. This study assessed the role of SWR on coastal dune ecosystem dynamics by combining field observations and laboratory experiments with theoretical ecological modeling that incorporated the empirically established relationships. We observed large differences in soil infiltration capacity in the field, and the laboratory experiments showed that soil hydrophobic compound concentrations and
\end{abstract}

antecedent soil moisture conditions can explain these differences. Theoretical model analyses suggested that SWR can trigger cyclic vegetation dynamics, including long periods in which vegetation is absent. Water competitive plants with low-hydrophobic compound content (for example, woody species) exhibit stable temporal dynamics, whereas species with opposite traits (for example, grasses) are more likely to induce cyclic dynamics. For the latter species, SWR can amplify drought stress. In northwest Europe, this effect could become more important in coming decades due to the projected increases in drought severity. Our study explains how SWR may contribute to coastal dune ecosystem complexity, providing insights that may aid effective dune conservation and restoration.

Key words: coastal dunes; cyclic dynamics; feedbacks; hydrophobic compounds; sandy soils; soil water repellency; water limitation.
Received 19 December 2015; accepted 6 April 2016;

published online 4 August 2016

Electronic supplementary material: The online version of this article (doi:10.1007/s10021-016-9995-9) contains supplementary material, which is available to authorized users.

Author contributions Conceived of or designed study: Siteur, Koen; Mao, Jiefei; Nierop, Klaas; Rietkirk, Max; Dekker, Stefan; Eppinga, Maarten Performed research: Siteur, Koen; Mao, Jiefei; Analyzed data: Mao, Jiefei; Contributed new methods or models: Siteur, Koen; Wrote the paper: Siteur, Koen; Mao, Jiefei

Koen Siteur and Jiefei Mao have contributed equally to this work. *Corresponding author; e-mail: k.siteur@gmail.com

\section{INTRODUCTION}

Coastal dune ecosystems provide a broad range of natural and socio-economic functions (Everard and others 2010), motivating conservation and restoration efforts in northwest Europe (Jensen 1994; Grootjans and others 2001; Van Der Meulen and others 2004a). Managing coastal dunes is complicated, as the stability and dynamics of these 
systems are controlled by an interplay between wind erosion, sand supply, and vegetation dynamics (Aagaard and others 2007; Klijn 1990a; Arens and others 2007). In turn, these factors are affected by on-going changes in climate and human activities. Due to the inherent complexity of coastal dunes, it is difficult to assess the impact of such changes on dune dynamics (Provoost and others 2009). Vegetation significantly contributes to the complexity of coastal dunes. Vegetation displays not only long-term dynamics with the abundance of dominant plant species varying over centuries (Zagwijn 1970) but also short-term dynamics driven by seasonality (Xu and others 2013). Seasonal changes in temperature and precipitation, for example, control the productivity of plants. In addition, vegetation in coastal dunes shows strong spatial heterogeneity and generally has a very diverse composition. Finally, complex developments of vegetation, such as retrogression, have been reported (Van Dorp and others 1985; Van der Maarel and others 1985).

To understand the factors that control the complexity of the coastal dune ecosystem, interactions between vegetation and the abiotic environment need to be considered (LeBagousse-Pinguet and others 2013; Adema and Grootjans 2003). In this context, the relationship between vegetation and available soil water deserves particular interest (Voortman and others 2015), as climate change is projected to include increasing severity of summer droughts in northwest Europe (KNMI 2014). This change may have undesired consequences for vegetation composition and cover, as well as groundwater recharge and wind erosion (Witte and others 2008). When considering potential responses to changing precipitation patterns, soil hydrophobicity, a widely observed property of dry sandy dune soils, may be important to consider (Dekker and Jungerius 1990; Ritsema and others 1993). This property is commonly referred to as soil water repellency (SWR). SWR is caused by hydrophobic compounds in the soil that mainly originate from plants (Bisdom and others 1993; DeBano 2000; Horne and McIntosh 2000; De Blas and others 2013) and to a lesser extent from microorganisms (Home 2015; McGhie and Posner 1980). These soil hydrophobic compounds differ in concentration and composition depending on their origin, and they also vary in their impact on SWR (Mao and others 2014, 2015). SWR is a potentially important driver of dune vegetation dynamics as it may hamper infiltration of water into the rootzone, thereby negatively affecting plant productivity. However, previous studies on SWR have mostly focused on soil characteristics (Dekker and Ritsema
1996; Doerr and others 2000a; Doerr and Thomas 2000) or on the identification of compounds at the molecular level (Franco and others 1995, 2000; De Blas and others 2013; Mao and others 2014, 2015). Hence, how SWR mediates the relationship between vegetation and soil water availability, and what the consequences of this altered relationship are for ecosystem functioning remains to be investigated.

To assess the role of SWR in coastal dune ecosystem functioning, the relative importance of feedbacks associated with SWR needs to be understood. Three feedbacks may potentially be important regarding the role of SWR on ecosystem level. The first feedback is a negative feedback between plants and available water, which results from the positive effect of available water on plant growth and the negative effect of plant biomass on water through water uptake. A second negative feedback is caused by accumulation of hydrophobic compounds in the soil through the decomposition of plant litter, which hampers infiltration and subsequent plant growth, resulting in less plant biomass and decreased litter production. Finally, a positive feedback could be caused by the fact that SWR only occurs on dry soils (Dekker and Ritsema 1994, 1996; Doerr and Thomas 2000). For a given amount of precipitation, SWR may cause dry soils to remain dry, whereas the same amount of precipitation may lead to additional wetting of (already) wet soils. The relative contribution of these feedbacks on ecosystem dynamics may depend strongly on plant species traits, such as water competitiveness, which controls the feedback between plants and available water, and hydrophobic compound content of plant tissue, which affects the accumulation of hydrophobic compounds in the soil and consequently its repellency. However, a systematic analysis of these three feedbacks within a modeling framework is required to understand how they interactively affect the coastal dune ecosystem dynamics.

This study aims to incorporate the described feedbacks into an ecological model in order to understand the role of SWR on coastal dune ecosystem functioning and to assess possible implications of projected climatic change for the complex vegetation dynamics of the coastal dune ecosystems. We did this by performing measurements and experiments using soil samples collected at a field site in the national park Zuid-Kennermerland (the Netherlands) to get insights regarding the effect of soil physical and soil chemical properties on SWR. The obtained relationships where then incorporated into an ecological model with 
which we aim to answer the following research questions: (i) what is the potential role of SWR on vegetation dynamics in the coastal dune ecosystem?; (ii) how do plant species traits affect the role of SWR on vegetation dynamics?; and (iii) how does SWR affect vegetation response to droughts with increasing severity?

\section{Empirical ObServations of SWR}

\section{Site Description}

The relationships used as input for the ecological model were obtained through experiments at a field site in a national park in northwest Europe (Zuid-Kennemerland, the Netherlands, $52^{\circ} 25^{\prime} 17^{\prime \prime} \mathrm{N}$, $\left.4^{\circ} 35^{\prime} 13^{\prime \prime} \mathrm{E}\right)$ and laboratory measurements and experiments using soil samples collected at the same site. Zuid-Kennemerland is a coastal sand dune system typical for the west of the Netherlands. A part of the study area is bare soil; however, most of it is covered by algae and various groups of plant species, including mosses, grasses, sedges, herbs, shrubs, and trees. In the area, annual rainfall amounts to $835 \mathrm{~mm} \mathrm{y}^{-1}$. The annual potential evapotranspiration is lower with $635 \mathrm{~mm} \mathrm{y}^{-1}$ but shows strong seasonal variability (KNMI 2015). As a result, monthly averaged potential evapotranspiration frequently exceeds precipitation during the months March to September, resulting in a precipitation deficit (see Figure 1). During this period, as water becomes scarce, plants start competing for water and can experience drought stress.

\section{Linking SWR to Infiltration}

To assess the role of SWR on ecosystem dynamics, we first examined how SWR is linked to infiltration. SWR is commonly measured using the water drop penetration time (WDPT) test (Van't Woudt 1959; Wessel 1988; Dekker and Ritsema 1994), which measures the time it takes for one water droplet to penetrate a soil. The level of SWR can then be classified in five groups (Bisdom and others 1993): wettable (0-5 s), slightly repellent (5-60 s), strongly repellent $(60-600 \mathrm{~s})$, severely repellent (600-3600 s), and extremely repellent (>3600 s). To link the WDPT to infiltration, we performed infiltration experiments in the dry season (July, 2015) on a bare and vegetated soil. Using the $W D P T$, we classified the soils (in the top $5 \mathrm{~cm}$ ) as being wettable and strongly/severely repellent, respectively. We then simulated a typical $5 \mathrm{~mm}$ rain event, which was applied instantaneously, while runoff of water was prevented using a ring with a diameter of $22 \mathrm{~cm}$.

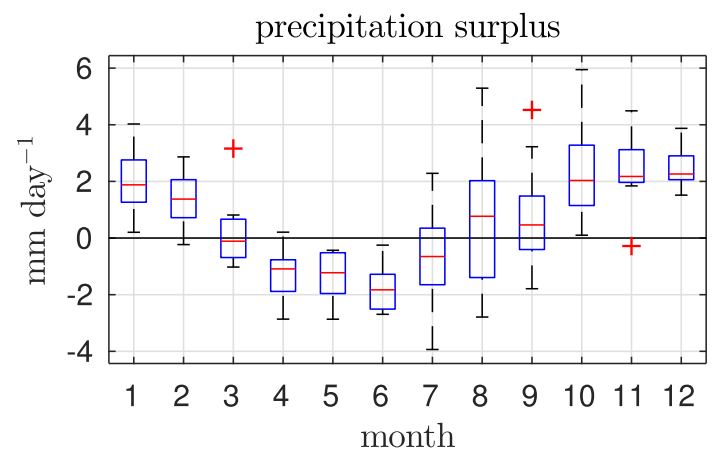

Figure 1. Monthly averages of daily precipitation surplus in $\mathrm{mm} \mathrm{day}^{-1}$ for the nearby weather station at Wijk aan Zee, The Netherlands (period: 01-05-2001-30-042015; location: $52^{\circ} 30^{\prime} \mathrm{N} 04^{\circ} 36^{\prime} \mathrm{E}$ ). The precipitation surplus was calculated by subtracting the (Makkink) potential evapotranspiration from the precipitation. The box and whisker plots show the median (central red lines) and the upper and lower quartiles (box limits) for each month. The whiskers indicate the variability outside the upper and lower quartiles and can extend to a maximum of 1.5 times the interquartile range. Values beyond the whiskers are regarded as outliers and indicated with the + markers (Color figure online).

Figure 2 shows that the resulting infiltration fronts differ strongly between the two soils. While the water infiltrates deep into the wettable soil (Figure 2A), it only wets the upper $1 \mathrm{~cm}$ of the repellent soil (Figure 2B). Water in this top layer can easily evaporate and therefore remains unavailable for plants whose root zones extend to much deeper layers. In addition, if not blocked by the ring, the water may be lost through runoff and infiltrate elsewhere. The common measure for SWR can therefore be considered as a good proxy for infiltration of water into the root zone.

\section{Soil Variables Controlling Infiltration}

We studied the effects two variables on infiltration: (i) hydrophobic compound concentration in the soil and (ii) initial soil moisture content. Links between these two variables and infiltration would give rise to feedbacks that potentially govern vegetation dynamics, as already briefly described in the introduction. To study the effects of these variables on infiltration, we collected 15 soil samples from the Zuid-Kennermerland under a variety of plant species (grasses, mosses, shrubs, pines, and oaks) at different soil depths ranging from 0 to $30 \mathrm{~cm}$ (see Mao and others 2014 for more sampling details).

To determine the hydrophobic compound concentration, all soil samples were oven-dried at $30^{\circ} \mathrm{C}$ for two days and sieved (mesh size $1.4 \mathrm{~mm}$ ) to remove leaf and root fragments. A sequential 
(A) wettable soil

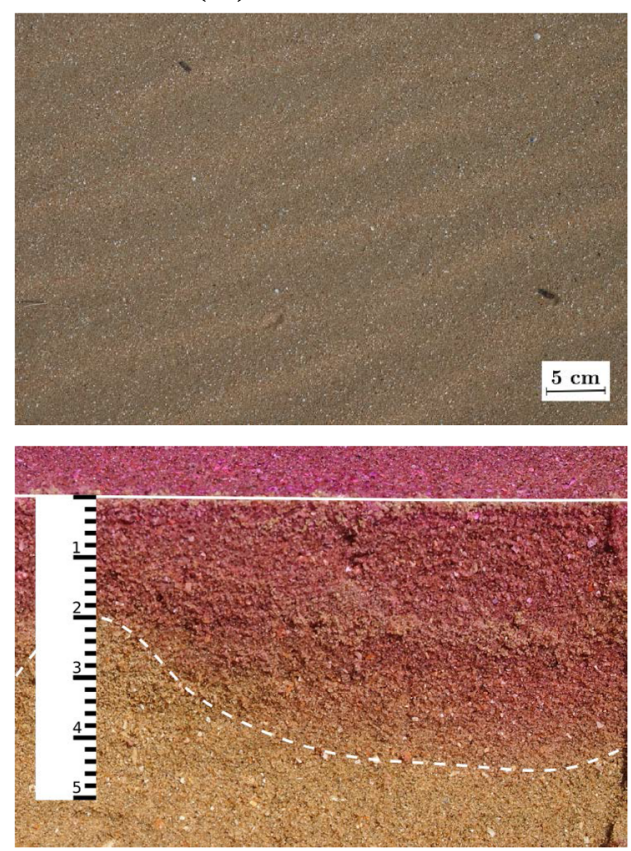

(B) strongly/severely repellent soil
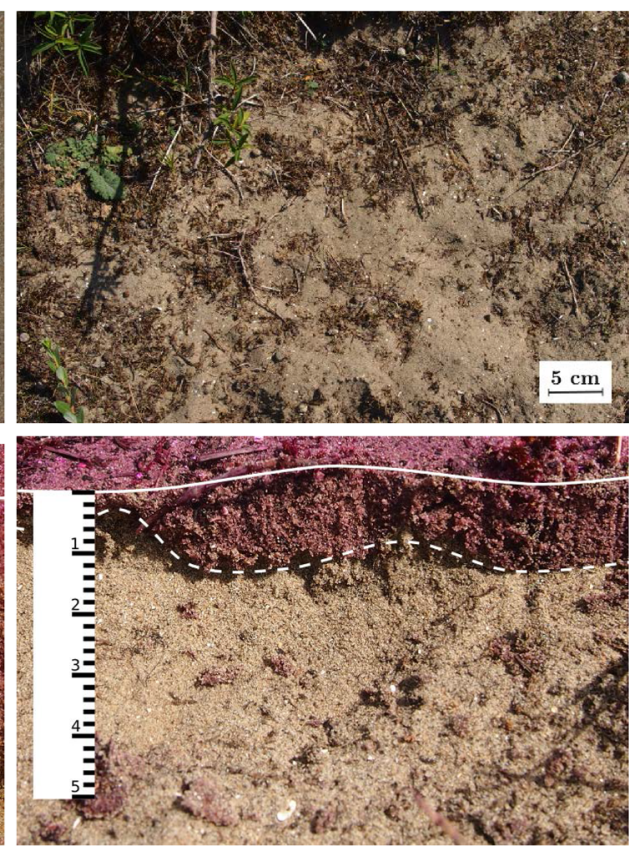

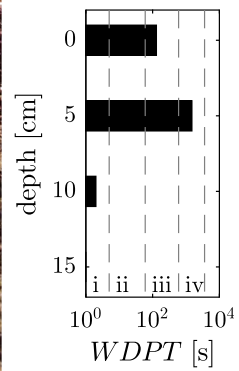

Figure 2. Infiltration fronts in a wettable soil $\mathbf{A}$ and a strongly/severely repellent soil $\mathbf{B} 1 \mathrm{~h}$ after a $5 \mathrm{~mm}$ rain event. The upper images show the undisturbed soil from above. The WDPT in soil A was $0 \mathrm{~s}$ along the whole soil profile. The WDPT of soil B is depicted in the bar graph, with classes (i) wettable, (ii) slightly repellent, (iii) strongly repellent, and (iv) severely water repellent. The WDPT for this soil equals zero for depths $>10 \mathrm{~cm}$ (Color figure online).

extraction procedure was applied to the soil samples using dichloromethane/methanol (DCM/ $\mathrm{MeOH}$ ) and iso-propanol/ammonia solution (IPA/ $\mathrm{NH}_{3}$ ) successively (Mao and others 2014). All extracts were analyzed by gas chromatography-mass spectrometry (GC-MS) to identify and quantify the compounds. The total hydrophobic compound concentration (THCC) in Figure 3 represents the summed concentration of the dominant compound groups extracted from soils as described by Mao and others (2015). For more details about the method and the identified compounds see Appendix A in Supplementary Materials. Figure 3A shows that the total hydrophobic compound concentration correlates with the WDPT, meaning that as hydrophobic compound concentration in the soil increases less water infiltrates. This finding suggests a negative feedback between plant biomass and available soil water: the accumulation of soil hydrophobic compounds through the decomposition of plant litter hampers infiltration and thereby negatively affects water availability and subsequent plant growth.

To determine soil moisture content, we selected a subset of samples. From each soil sample, $40 \mathrm{~g}$ of oven-dried soil was put in a plastic Petri dish (ø90 mm, $1.5 \mathrm{~mm}$ height). Demineralized water was added until the soil became saturated. The dishes were put in a fume hood to let water evaporate. As the water evaporated over time, the dishes were weighed to calculate the gravimetric soil moisture content and the WDPT was measured by applying 10 water droplets to each soil (see Appendix B in Supplementary Materials for the equation used to calculate the gravimetric soil moisture content). Figure 3B shows that, in line with previous studies (Dekker and Ritsema 1994; Doerr and Thomas 2000; Dekker and Ritsema 1996), a SWR threshold in soil moisture can be identified below which infiltration is hampered. Above this threshold, soils are wettable and infiltration is possible. The finding suggests the potential of a positive feedback between soil water availability and infiltration: a decrease in soil water reduces infiltration, leading to a further decrease in soil water.

\section{Model Description and Analyses}

\section{Model Description}

A theoretical model was developed which captures our three empirical observations: (1) SWR hampers infiltration into the root zone (Figure 2B), (2) SWR increases with hydrophobic compound concentra- 

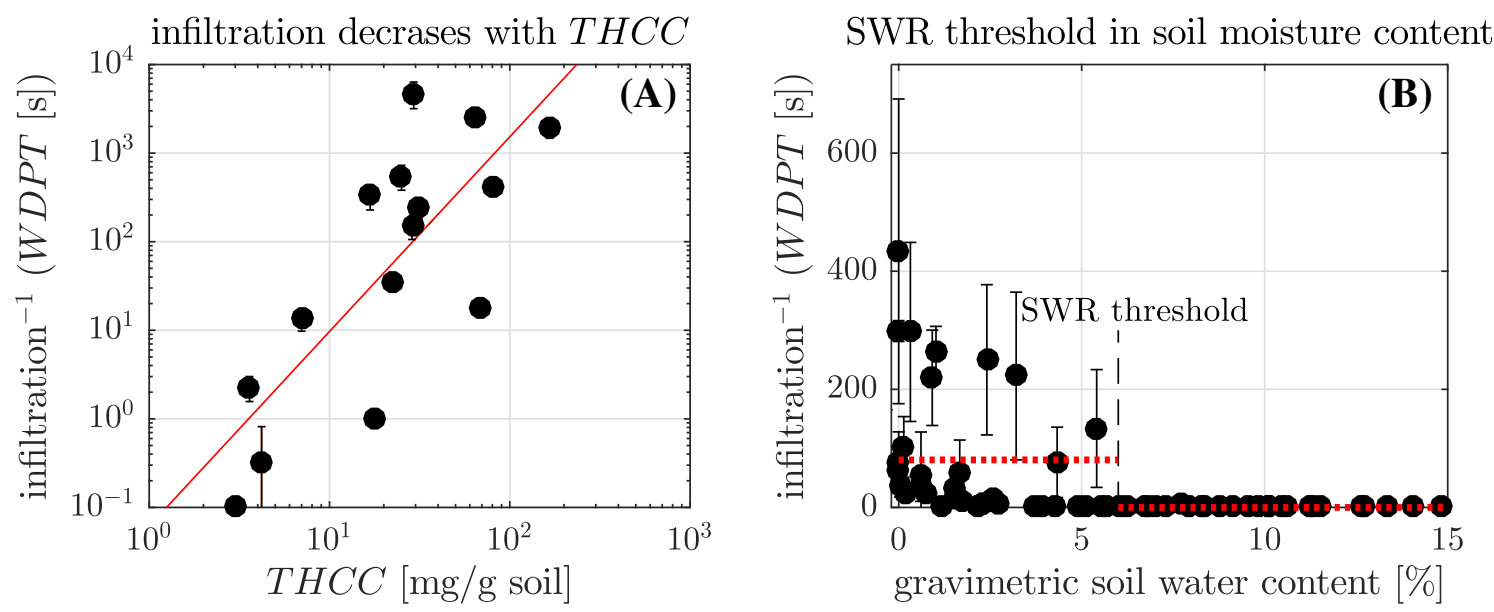

Figure 3. A Infiltration, measured as the inverse of the water droplet penetration time $\left(W D P T^{-1}\right)$, decreases with the total hydrophobic compound concentration (THCC). A linear fit through this log-log plot gives the following equation: WDPT $=10^{b}$ THCC $^{a}$ with $a=2.1979, b=-1.2115, R^{2}=0.61$, and $p=0.0006$. The dots and the whiskers in this plot represent the average \pm the standard deviation of the penetration times of 20 individual water droplets on oven-dried soil samples. B SWR only occurs if the gravimetric soil moisture content drops below a threshold value of around $6 \%$. Here the dots and the whiskers are based on the measured penetration times of 10 individual water droplets. The red dotted lines are the average WDPT below and above the threshold. More details about the methods can be found in Appendix B in Supplementary Materials (Color figure online).

tion (Figure 3A), and (3) SWR occurs only in dry soils (Figure $3 \mathrm{~B}$ ). The model is based on the water limitation model by Rietkerk and others (1997), which was extended to include these observations. The model captures the dynamics in available soil water $W(\mathrm{~mm})$, plant biomass $B\left(\mathrm{~g} \mathrm{~m}^{-2}\right)$, and hydrophobic compound density $C\left(\mathrm{~g} \mathrm{~m}^{-2}\right)$. All state variables are assumed to be uniformly distributed in space.

The dynamics in available water $W$ are modeled with Eq. (1):

$$
\frac{\mathrm{d} W}{\mathrm{~d} t}=p I(W ; C)-U(W) B-r W .
$$

The first term represents the infiltration of water into the root zone. Here $p$ is the precipitation rate $\left(\mathrm{mm}\right.$ day $\left.^{-1}\right)$ and $I$ is the fraction of the precipitation that infiltrates into the root zone $(-)$. This fraction depends on the amount of water in the root zone $W$ and the amount of hydrophobic compounds $C$ :

$$
I(W ; C)=\frac{W^{\alpha}+W_{0}(C) k_{1}^{\alpha}}{W^{\alpha}+k_{1}^{\alpha}} .
$$

In Eq. (2), $k_{1}$ is the SWR threshold (mm) that we identified in Figure 3B. It is the value of $W$ below which infiltration into the root zone is hampered. Above this value, $I$ asymptotically approaches 1 as
$W$ increases, meaning that all water infiltrates into the root zone. Below $k_{1}$, as $W$ decreases, $I$ approaches a value of $W_{0}$, which is the fraction of precipitation that infiltrates into dry soil. The steepness of the SWR threshold is controlled by the dimensionless exponent $\alpha[-](\alpha \gg 1)$. To capture the increase in SWR with hydrophobic compound concentration (Figure 3A), we let the fraction of precipitation that infiltrates into dry soils $W_{0}$ decline with hydrophobic compound density in the soil $C$ as given by Eq. (3):

$$
W_{0}(C)=\frac{k_{2}}{C+k_{2}} .
$$

Here $k_{2}$ is a half saturation constant $\left(\mathrm{g} \mathrm{m}^{-2}\right)$, it is the hydrophobic compound abundance at which the fraction of precipitation that infiltrates into dry soils equals $1 / 2$. The remaining terms of Eq. (1) represent soil water uptake by plants (second term) and losses (third term) and are modeled as by Rietkerk and others (1997). The uptake by plants is linearly related to plant biomass density $B$ and asymptotically approaches a maximum uptake rate of $u\left(\mathrm{dm}^{3} \mathrm{~g}^{-1} \mathrm{day}^{-1}\right)$ as the available water increases:

$$
U(W)=\mu \frac{W}{W+k_{3}} .
$$


Here $k_{3}$ is the value of $W$ at which the uptake is half the maximum uptake rate $(\mathrm{mm})$. Water losses, for example, through percolation out of the root zone, are linearly related to the available water $W$ and occur at a rate of $r\left(\right.$ day $\left.^{-1}\right)$.

The dynamics in plant biomass $B$ are modeled as by Rietkerk and others (1997):

$$
\mathrm{d} B / \mathrm{d} t=c U(W) B-m B
$$

The first term represents plant growth, which increases linearly with water uptake (Eq. 4). Parameter $c$ is the conversion coefficient of water uptake by plants to plant growth $\left(\mathrm{g} \mathrm{dm}^{-3}\right)$. The second term covers mortality losses, which increases linearly with plant biomass density $B$. Parameter $m$ is the specific biomass loss rate $\left(\right.$ day $\left.^{-1}\right)$.

The model by Rietkerk and others (1997) was further extended with Eq. (6), which captures the accumulation and decomposition of hydrophobic compounds in the soil:

$$
\mathrm{d} C / \mathrm{d} t=f m B-d C .
$$

The accumulation of hydrophobic compounds occurs at the rate at which litter is produced $\mathrm{mB}$ $\left(\mathrm{g} \mathrm{m}^{-2}\right.$ day $\left.^{-1}\right)$ multiplied with the fraction of hydrophobic compounds in plant tissue $f\left(\mathrm{~g} \mathrm{~g}^{-1}\right)$. The decomposition of hydrophobic compounds takes place at a constant rate of $d\left(\mathrm{day}^{-1}\right)$. All parameters in the model are listed and briefly described in Table 1.

Figure 4 shows the feedbacks in the described model. In the model, water promotes plant growth while plants deplete water, resulting in a negative feedback between plants and water ( $\left.I_{-}\right)$. Plants also produce hydrophobic compounds that potentially hamper infiltration, leading to less available water and decreased plant growth, which yields a second negative feedback loop (II_). However, because wet soils allow infiltration, the negative effect of hydrophobic compounds is diminished by water in the soil, thereby yielding a positive feedback $\left(\mathrm{III}_{+}\right)$.

The three feedbacks depicted in Figure 4 do not occur at the same timescales. The effects of hydrophobic compounds and water on infiltration are instantaneous, meaning that the positive feedback $\left(\mathrm{III}_{+}\right)$is fast. Plant dynamics, on the other hand, take place at longer time scales than infiltration, resulting in a slower plant-water feedback (I-). The negative plant-compound-water feedback (II_) can be considered to be even slower because

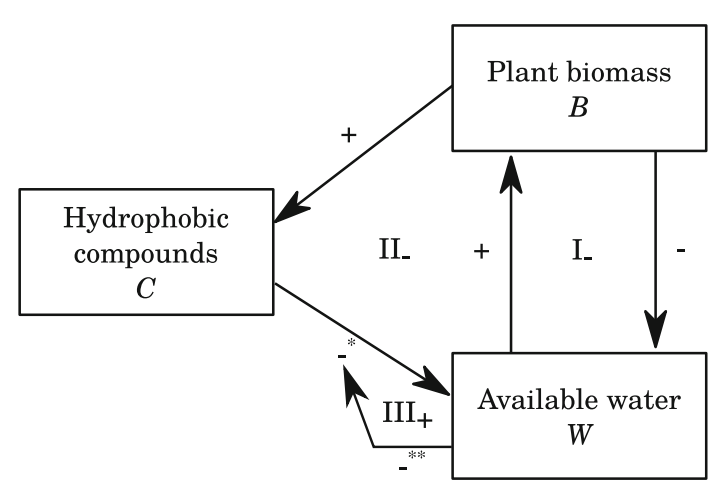

Figure 4. Interactions between the model components and the resulting feedbacks. Interactions are represented by the arrows and feedbacks are indicated with the Latin numbers and are described in the main text. The + and signs indicate positive and negative interactions/feedbacks, respectively. The asterisks * and ** refer to interactions derived from the empirical observations in ZuidKennermerland presented in Figures 3A, B, respectively.

Table 1. Description and Units of the Model Parameters and State Variables

\begin{tabular}{lll}
\hline Symbol & Description & Unit \\
\hline$W$ & Available soil moisture & $\mathrm{mm}^{-2}$ \\
$B$ & Plant biomass density & $\mathrm{g} \mathrm{m}^{-2}$ \\
$C$ & Hydrophobic compound density & $\mathrm{g} \mathrm{m}^{-2}$ \\
$\alpha$ & Exponent causing a threshold the infiltration function & - \\
$c$ & The conversion of water uptake by plants to plant growth & $\mathrm{g} \mathrm{dm}^{-3}$ \\
$d$ & Decomposition rate of hydrophobic compounds & $\mathrm{day}^{-1}$ \\
$f$ & Fraction of hydrophobic compounds in plant tissue & $\mathrm{g} \mathrm{g}^{-1}$ \\
$k_{1}$ & SWR threshold in the infiltration function & $\mathrm{mm}^{-2}$ \\
$k_{2}$ & Half saturation constant of infiltration into dry soil & $\mathrm{g} \mathrm{m}^{-2}$ \\
$k_{3}$ & Half saturation constant of soil water uptake & $\mathrm{mm}^{-1}$ \\
$m$ & Specific loss of biomass due to mortality and grazing & $\mathrm{day}^{-1}$ \\
$p$ & Precipitation rate & $\mathrm{mm} \mathrm{day}^{-1}$ \\
$r$ & Specific soil water loss & $\mathrm{day}^{-1}$ \\
$\mu$ & Maximum specific water uptake & $\mathrm{dm}^{3} \mathrm{~g}^{-1} \mathrm{day}^{-1}$ \\
\hline
\end{tabular}


hydrophobic compounds accumulate and decompose at a very low rate, due to the small fraction of hydrophobic compounds in plant tissue and the low decomposition rate of hydrophobic compounds (see Appendices D and E for observed fractions and rates, respectively).

\section{Model Analysis}

To understand the potential role of SWR in dune vegetation dynamics, the model was analyzed qualitatively, complemented with numerical simulations. The parameter values where adopted from Rietkerk and others (1997) and parameters $f$, $d, k_{1}$, and $k_{2}$ have order-of-magnitude values that are based on our observations and related observations published elsewhere (Mao and others 2015; see Appendices D and E). For more details on the parameter values and a list of the values per figure, see Appendix C in Supplementary Materials.

During analysis, it was assumed that the dynamics of the three state variables occur at different rates $\mathrm{d} W / \mathrm{d} t>\mathrm{d} B / \mathrm{d} t>\mathrm{d} C / \mathrm{d} t$. This assumption enables separating the timescales at which these dynamics occur, which helps in obtaining a mechanistic understanding of the model dynamics. In the section 'SWR-induced Bistability in Soil Conditions', we first study the dynamics in the fast state variable $W$, while treating the slow dynamics in $B$ and $C$ as being static (that is, as parameters). In the section 'The Water-Plants Cycle: Repetitive Regime Shifts', we add complexity by treating both $W$ and $B$ as dynamic state variables. In the section 'Cyclic Dynamics and the SWR Lock', we consider the full model and discuss the effect of dynamic $C$.

To study how the vegetation dynamics are affected by plant species traits, the steady state

without hydrophobic compounds

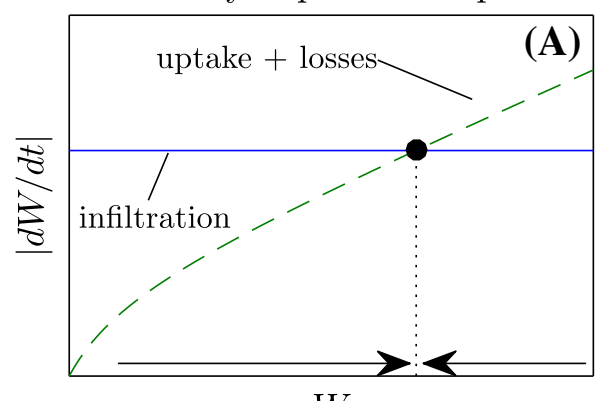

$W$ behavior of the model was studied for different combinations water competitiveness, which is controlled by a number of different parameters, and the fraction of hydrophobic compounds in plant tissue $f$, which differs between species as shown in Appendix D in Supplementary Materials.

To study the role of SWR in droughts and the effect of increasing drought severity, droughts were simulated by reducing the precipitation rate $p$ with 10,20 , and $40 \%$ for soils with and without hydrophobic compounds.

\section{Model Results}

\section{SWR-induced Bistability in Soil Conditions}

When treating the state variables plant biomass $B$ and hydrophobic compound density $C$ as parameters, the system can be analyzed by plotting the positive terms and the negative terms of Eq. (1) against available soil water $W$, as shown in Figure 5. Water availability $W$ increases where infiltration (positive) exceeds the sum of water uptake and losses from the soil (negative). The available water $W$ decreases where infiltration exceeds the negative terms. For a soil without hydrophobic compounds, this means that $W$ asymptotically approaches the relatively wet equilibrium state depicted in Figure 5A, where infiltration equals uptake plus losses. For a soil with hydrophobic compounds, the dynamics in available water are more complex. Hydrophobic compounds induce water repellency of dry soils (Figure 3B) preventing water from infiltrating into the rootzone (Figure $2 \mathrm{~B}$ ). This positive feedback mechanism results in three intersections of the infiltration curve with

with hydrophobic compounds

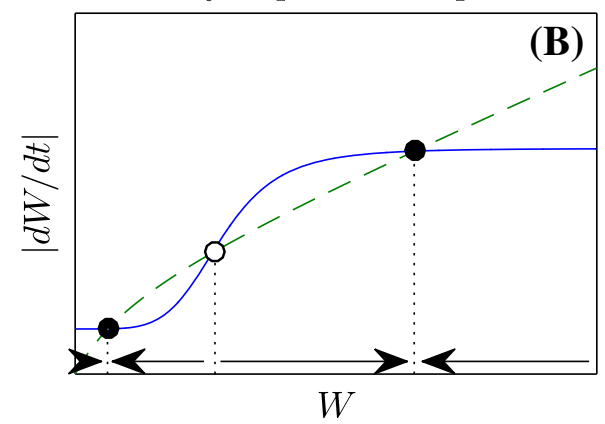

Figure 5. The positive (solid blue) and negative (dashed green) terms of Eq. (1) plotted against available water $W$, for soils without hydrophobic compounds $(\mathbf{A})$ and with hydrophobic compounds $(\mathbf{B})$. Stable and unstable equilibria are depicted with the closed and open dots, respectively. The arrows show the dynamics of the system when it is out of equilibrium. Available water increases where infiltration exceeds the uptake and losses, and decreases where the opposite occurs. For parameter values see Appendix C in Supplementary Materials (Color figure online). 
the uptake and loss curve, as shown in Figure 5B. Two of these equilibrium states are stable (they attract) and one is unstable (it repels). The system resides in one of the stable equilibrium states, meaning that soils are either wet and hydrophilic or dry and hydrophobic.

\section{The Water-Plants Cycle: Repetitive Regime Shifts}

Changes in infiltration and uptake may change the number of equilibrium states in soils that contain hydrophobic compounds. A decrease in rainfall $p$ for example can lower the infiltration curve such that the hydrophilic wet state shown in Figure 5b vanishes. If the soil is in this state, a decrease in rainfall can trigger a sudden shift to a hydrophobic dry state, as we will discuss in the section 'SWR Can Amplify Drought Stress'. In our model, however, such shifts need not be driven by external changes but may also be triggered by changes in plant biomass density. Plants may thrive and increase in biomass on the wet hydrophilic soils, but may not survive and decrease in biomass at dry hydrophobic soils. The gradual increase in water uptake from wet soils can initiate a shift to hydrophobic dry soils, as shown in Figure 6A (I-IIIII). On hydrophobic dry soils plant biomass decreases and water uptake declines eventually resulting in a shift back to hydrophilic wet soils (III-IV-I). The coupled plant and water dynamics are therefore responsible for repetitive shifts between the two stable equilibrium states of $W$ (Figure $6 \mathrm{~B}$ ). These repetitive regime shifts are fully internally driven, meaning that they occur without any external forcing.

\section{Cyclic Dynamics and the SWR Lock}

As plants grow and litter is produced, hydrophobic compounds accumulate in the soil. Over time, the system therefore moves from having one stable equilibrium state (Figure 5A) to a bistable system (Figure $5 \mathrm{~B}$ ), thereby giving rise to the repetitive regime shifts discussed in the previous section. Figures 7A, B show the phase planes of these two qualitatively different system modes. They show that, as hydrophobic compound density
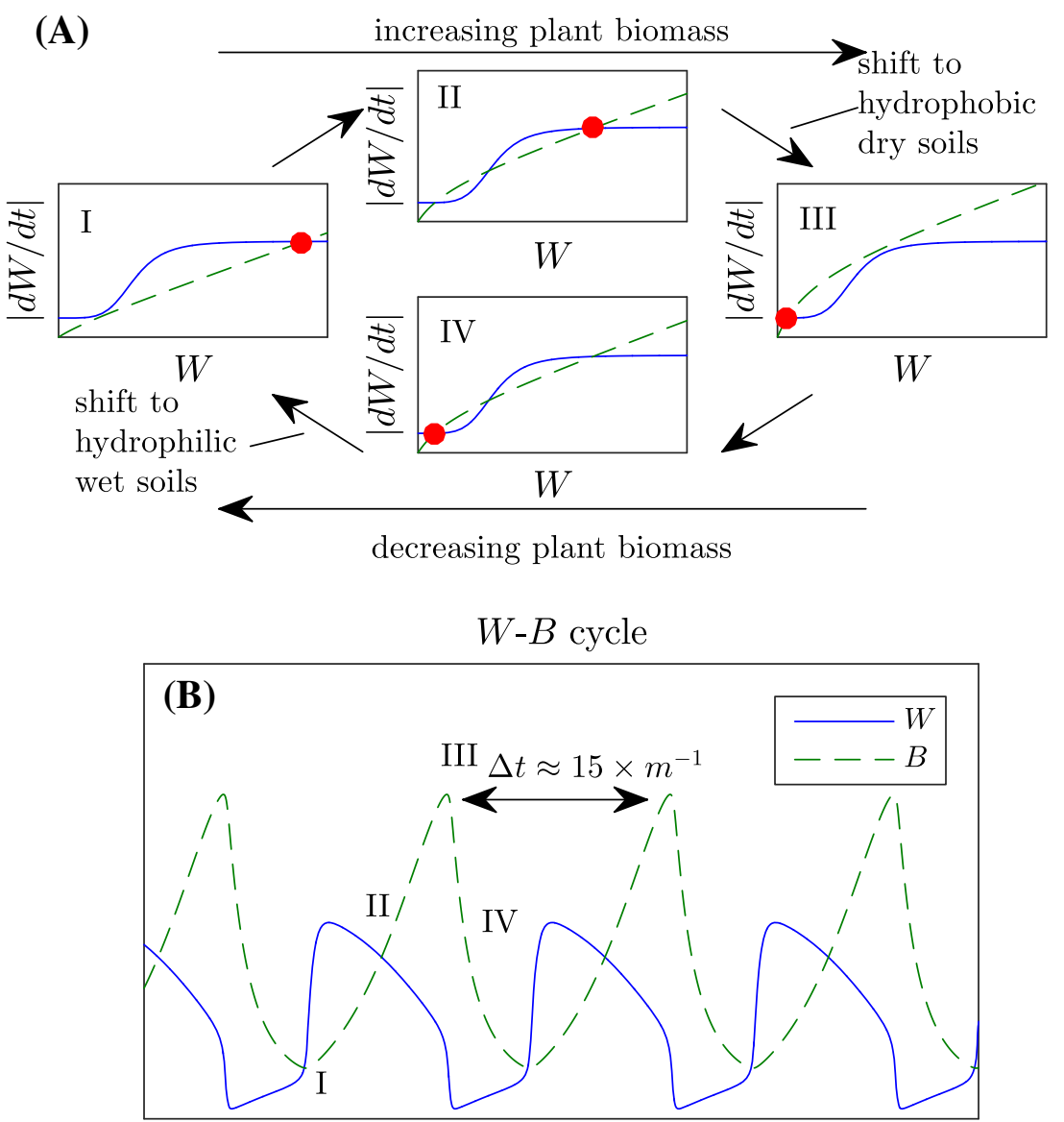

time $t$
Figure 6. Repetitive regime shifts in available water. A The positive (solid blue line) and negative (dashed green line) terms of Eq. (1) plotted against available water $W$, for a soil with hydrophobic compounds and dynamic plant growth. The red dot indicates the system state. B The dynamics in available water $W$ and plant biomass $B$ over time. The period of the cycles with the current parameter setting is just over 1 year, which corresponds to approximately 15 plant generations $\left(\mathrm{m}^{-1}\right)$. For parameter values, see Appendix $\mathrm{C}$ in Supplementary Materials (Color figure online). 


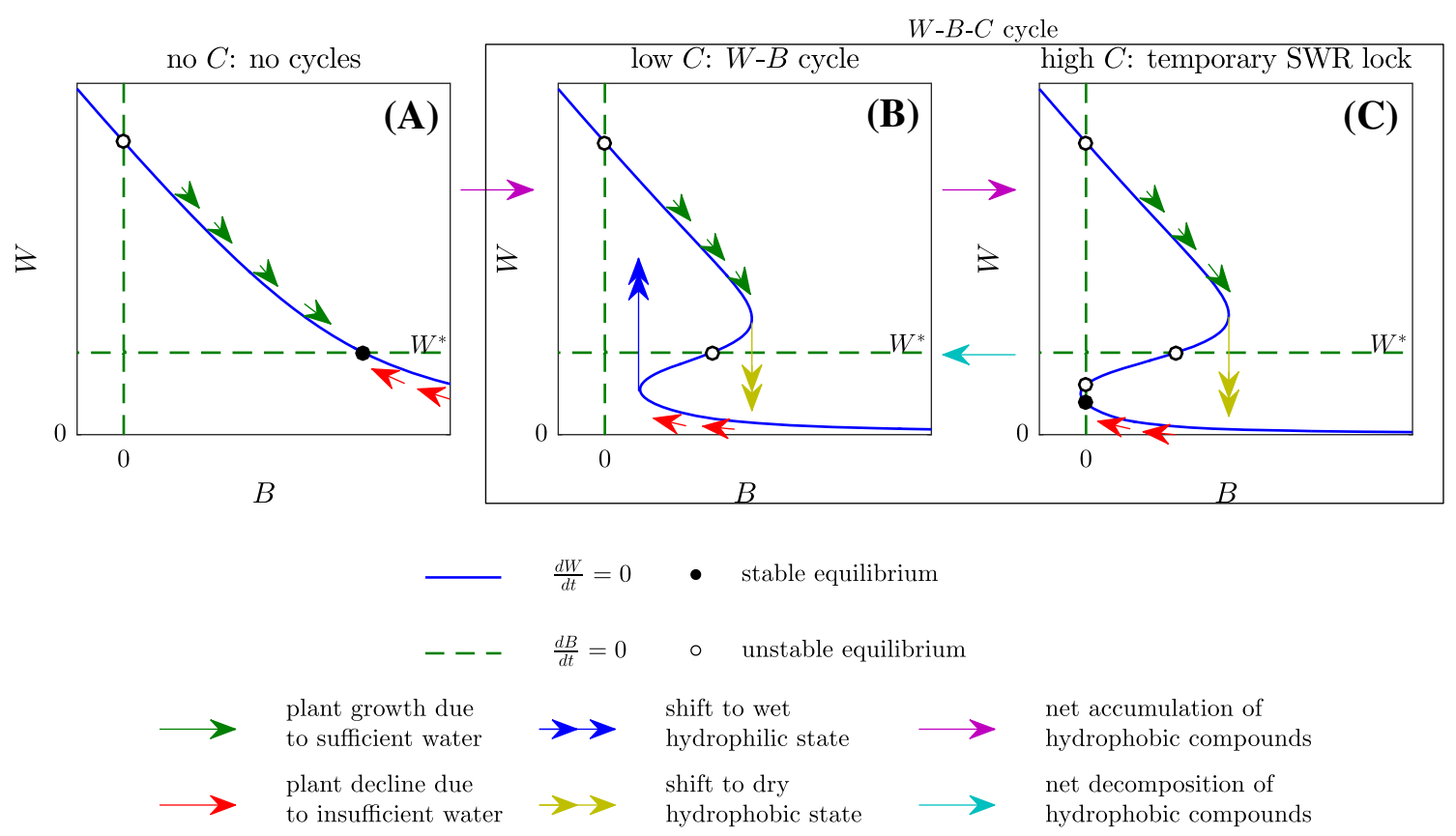

Figure 7. Phase planes for the model with different levels of hydrophobic compound density $C$. Above the horizontal plant isocline (green dashed line), plant density increases as a result of abundant available water. Below the plant, isocline plant density decreases due to insufficient available water. Left from the water isocline (blue solid line), water increases due to a low uptake rates by plants. Right from the water isocline, water decreases as a result of elevated uptake rates. As the dynamics in available water are fast with respect to the plant dynamics, the system will usually be close to the water isocline. For parameter values, see Appendix C in Supplementary Materials (Color figure online).

$C$ increases, the stable equilibrium state becomes unstable after which the system alternates between two branches of the $W$-isocline. Figure 7C shows that for high $C$ there is a third system mode, in which the transition from a hydrophobic dry soil to a hydrophilic wet soil is blocked by a stable equilibrium state that emerges on the lower branch of the $W$-isocline. At this stable equilibrium state, which we will call the SWR lock, plant density equals zero. This means that there is no accumulation of hydrophobic compounds and that over time, as hydrophobic compounds decompose, the SWR lock vanishes. The gradual accumulation and decomposition of hydrophobic compounds gives rise to a second cycle, the $W-B-C$ cycle (see Figure 8), in which the system alternates between the two system modes depicted in Figure 7B, C. Because the dynamics in $C$ are slower than the plant dynamics, this second cycle comprises a longer time interval than that of the repetitive shifts of the $W-B$ cycle.

\section{The Impact of SWR Depends on Plant Species Traits}

The plant species traits that are included in this model can be captured with only two variables. The first variable is $W^{*}$, the $B$-isocline of Figure 7 , which is given by:

$$
W^{*}=\frac{m k_{3}}{c u-m} \text {. }
$$

The $W^{*}$ gives the minimum resource abundance required for plant biomass to increase and is therefore inversely related to the water competitiveness of a species: species with low $W^{*}$ will eventually outcompete species with high $W^{*}$ (sensu Tilman 1982). The second variable is the fraction of hydrophobic compounds in plant litter $f$, which appears to vary between plant species as shown in Appendix D in Supplementary Materials and controls the accumulation rate of hydrophobic compounds $(=f m B)$ and consequently the equilibrium value of $C$.

Figure 9 shows the equilibrium plant biomass $B$ for different combinations of water competitiveness $\left(W^{*}\right)^{-1}$ and hydrophobic compound fraction $f$. It shows that the previously described $W-B$ cycles occur only in a system with species that contain sufficient hydrophobic compounds and that have an intermediate water competitiveness. Species with a high water competitiveness do not display cyclic dynamics, as these species can cope with the 


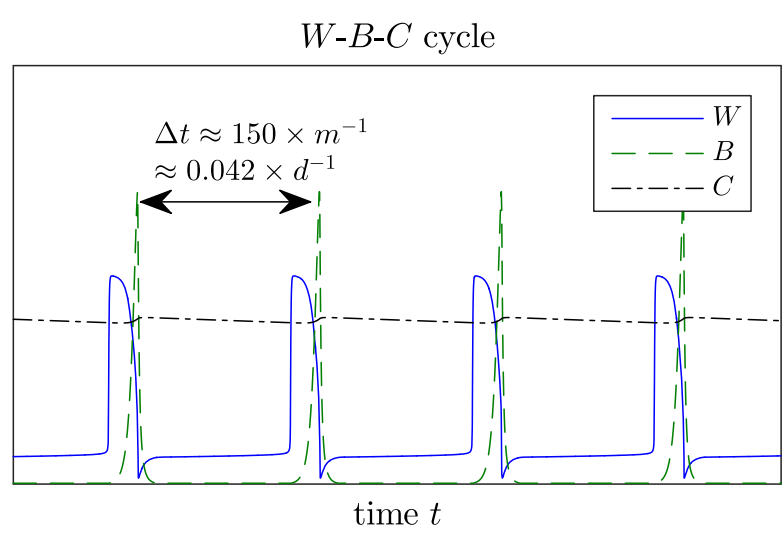

Figure 8. The dynamics in available water $W$, plant biomass $B$, and hydrophobic compound density $C$ over time. The period of the cycles for the current parameter setting is just over 10 years, which corresponds to approximately 150 plant generations $\left(m^{-1}\right)$ or 0.042 times the mean residence time of hydrophobic compounds $\left(d^{-1}\right)$. For parameter values, see Appendix $C$ in Supplementary Materials. $C$ was scaled to match the order of magnitude of $B$ and $W$ (Color figure online).

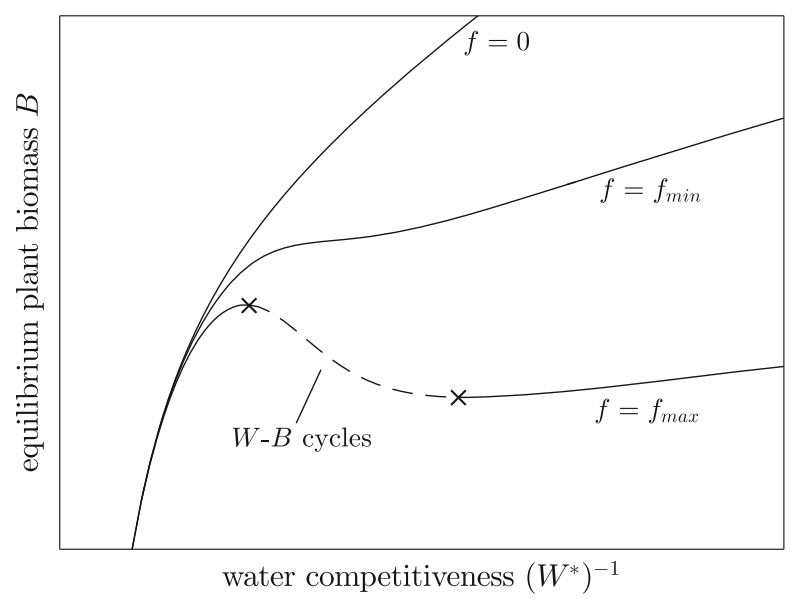

Figure 9. Water competitiveness $\left(W^{*}\right)^{-1}$ and the fraction of hydrophobic compounds in plant litter $f$ control the equilibrium plant biomass and the emergence of cyclic dynamics. $f_{\min }\left(=0.0008 \mathrm{~g} \mathrm{~g}^{-1}\right)$ and $f_{\max }\left(=0.0065 \mathrm{~g} \mathrm{~g}^{-1}\right)$ are the minimum and maximum measured value of $f$, respectively, as listed in Appendix D in Supplementary Materials. For the other parameter values, see Appendix $\mathrm{C}$ in Supplementary Materials.

dry conditions of hydrophobic soils such that plant biomass does not decrease to a level required for the shift from a hydrophobic dry state to a hydrophilic wet state. However, the equilibrium biomass of these competitive species is significantly reduced by SWR. This can be attributed to the fact that SWR only affects the dry soils on which these species live. Species with a low water competitiveness only live on wet soils that are unaffected by SWR, and therefore, their equilibrium biomass remains unaffected even if the fraction hydrophobic compounds in their litter is high. However, as we will show in the next section, the combination of SWR and droughts can significantly affect these species.

\section{SWR Can Amplify Drought Stress}

The equilibrium states discussed in the previous section and shown in Figure 9 represent the longterm dynamics of the undisturbed coastal dune ecosystem. However, the precipitation surplus strongly varies within one year (Figure 1), and this variability is projected to increase over the coming decades (KNMI 2014). Figure 10 shows how droughts of increasing severity affect a species that has a low water competitiveness on soils with and without hydrophobic compounds. For soils without hydrophobic compounds, plants respond in a rather linear way to a sudden drop in precipitation $p$, regardless of the drought severity. For plants on soils that do contain hydrophobic compounds, the system response depends on drought severity. Minor droughts result in a similar linear response in vegetation as for soils without hydrophobic compounds. Slightly more severe droughts, however, have a disproportional effect on both available water and plant biomass. This is caused by a temporary shift from a hydrophilic wet state to a hydrophobic dry state (that is, a single $W-P$ cycle is triggered). An even greater reduction in precipitation can trigger a permanent shift to a hydrophobic dry state. Here the system gets trapped in the SWR lock, which leads to extinction of the species and can only be undone by an increase in precipitation or, on longer timescales, by decomposition of hydrophobic compounds. In Appendix F in Supplementary Materials, we show that the presented shifts can only be triggered by a rapid decline in rainfall, for example, by seasonality, and that a gradual decline in precipitation leads to a linear system response. We also show that increasing precipitation back to the original value allows soils to shift back to a hydrophilic wet state and enables vegetation to recover. Finally, we show that, in contrast to the weak competitor modeled here, competitive species always respond in a linear way to declines in precipitation.

\section{Discussion and Conclusions}

In this study, we obtained relationships governing soil water repellency (SWR) from field and laboratory experiments to develop an ecological model 

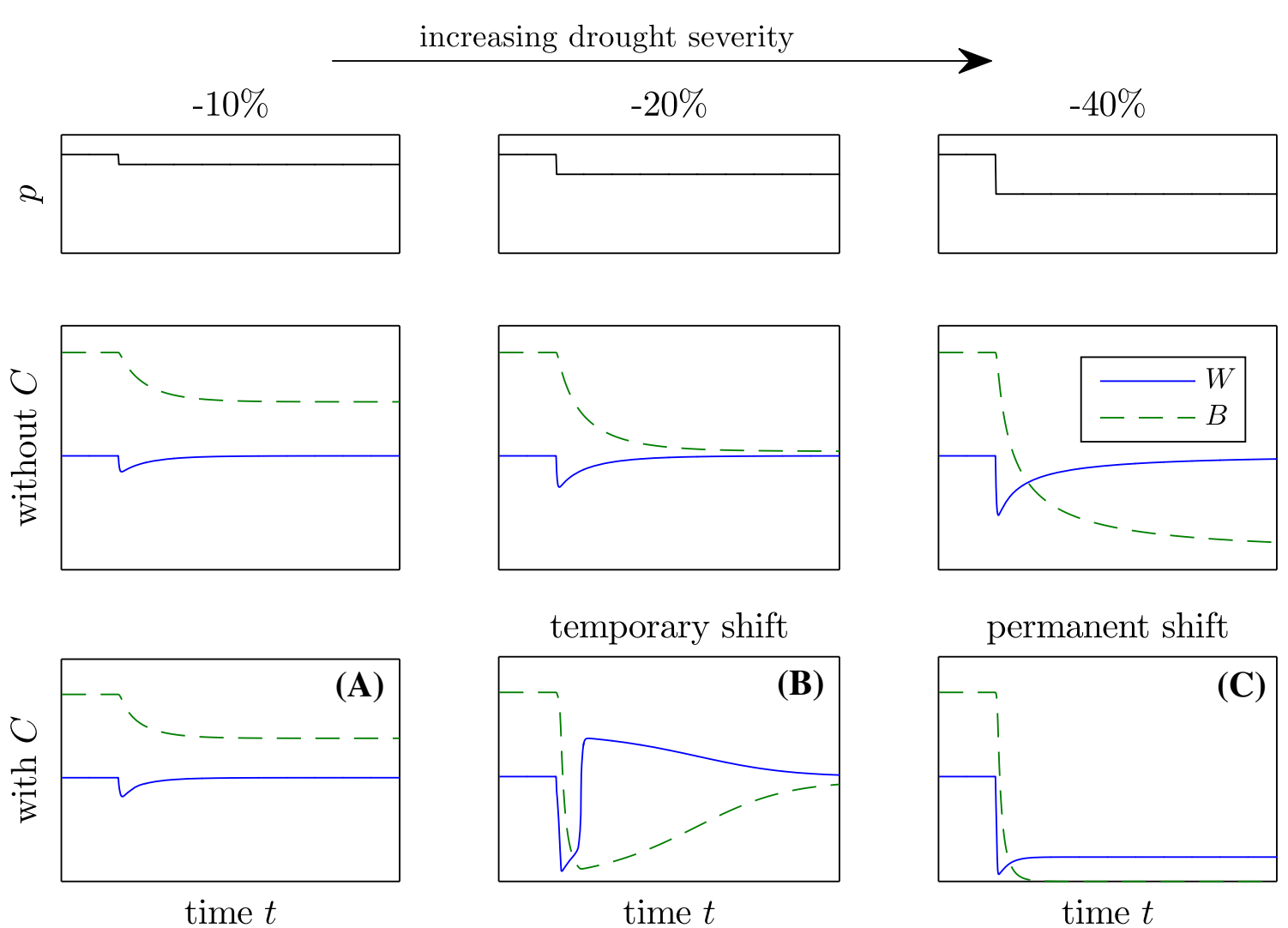

Figure 10. Amplification of drought stress for species with low water competitiveness caused by a (temporary) shift to the hydrophobic dry state. A period of 3000 days was modeled, which corresponds to 105 plant generations $\left(m^{-1}\right)$. For parameter values, see Appendix C in Supplementary Materials. For runs with gradually declining precipitation, runs with precipitation increasing back to the original values and runs with a competitive species see Appendix F in Supplementary Materials (Color figure online).

which enabled us to systematically study the role of SWR in the vegetation dynamics of coastal dune ecosystems. The model suggests that SWR can result in bistable soil conditions (Figure 5B), meaning that soils are either in a hydrophilic wet state or in a hydrophobic dry state. If plants increase their biomass on hydrophilic wet soils and decrease their biomass on hydrophobic dry soils then cyclic vegetation dynamics can be triggered, in which soils alternate between the two stable states in soil water (Figure 6). The accumulation of soil hydrophobic compounds may trigger a SWR lock, which interrupts the water-plant cycle (Figure 7) and gives rise to a water-plants-hydrophobic compounds cycle which is characterized by long periods in which vegetation is absent (Figure 8 ). The emergence of these cycles strongly depends on two plant species traits: (i) hydrophobic compound concentration in plant tissues and (ii) water competitiveness (Figure 9). Cyclic dynamics only occur if plant tissues contain a relatively high fraction of hydrophobic compounds. Depending on their water competitiveness, plants are affected by SWR in three dif- ferent ways. Species with intermediate water competitiveness display SWR-induced cyclic dynamics. Competitive species do not exhibit such cyclic dynamics but for these species SWR significantly reduces their productivity and equilibrium biomass. Cyclic dynamics are also not exhibited by species with low water competitiveness. However, such species are very sensitive to droughts. Depending on drought severity, soils covered by species with low water competitiveness may temporally or permanently shift to a hydrophobic dry state (Figure 10). This can result in a significant reduction in plant biomass or even a permanent shift to a bare state.

As noted above, our study highlights the importance of two species traits in coastal dune ecosystems: hydrophobic compound content of plant tissues and water competitiveness. The hydrophobic compound contents of woody species, for example, pine and oak, are lower than of grasses (for example, sheep fescue, red fescue, tufted grass; see Appendix D in Supplementary Materials). Water competitiveness is likely to be 
higher for woody plants than for grasses, herbs, and mosses, since woody plants generally have deeper roots and lower wilting point (Scholes and Walker 2004). Our model suggests that species with high water competitiveness and low-hydrophobic compound content, that is, woody species, are likely to exhibit stable vegetation dynamics, while less competitive species, that is, grasses, would display cyclic dynamics or strong drought sensitivity.

Apart from the short-term dynamics, our model suggests that SWR may also be important on longer timescales. As it can take centuries for hydrophobic compounds to decompose (see Appendix E in Supplementary Materials), their gradual accumulation may result in long periods in which vegetation is absent (the SWR lock; see Figure 8). This, in combination with climatic variations and increased wind erosion during the absence of stabilizing vegetation, may contribute to the long-term vegetation dynamics reported by Zagwijn (1970). Our model also suggests that SWR can increase the sensitivity of the dune ecosystem to disturbances such as shifts in precipitation (see Figure 10). Such disturbances are thought to be an important mechanism behind retrogression (Peltzer and others 2010), which has been observed in dune systems of northwest Europe Van der Maarel and others 1985; Van Dorp and others 1985). Our model suggests that, even in the absence of disturbances, SWR can result non-linear biomass development associated with retrogression (see Figure 8).

Although our study shows that SWR is a potential driver of vegetation dynamics, externally driven shifts in vegetation composition could also change water repellency of soils. An example of such a community shift is the widely reported problem of grass encroachment, caused by elevated nitrogen deposition rates (Kooijman and Van der Meulen 1996); Veer and Kooijman 1997; Kooijman and others 1998; Veer 1997a; van den Berg and others 2005; Remke and others 2009. Grasses have a high hydrophobic compound content (see Appendix D in Supplementary Materials) and may therefore enhance SWR. In addition to shading (Veer and Kooijman 1997), this may be an important mechanism to outcompete other plant species.

Focusing on dune ecosystems, our study raises the question whether our findings apply to other ecosystems with different climates and soil textures. Besides requiring water-limiting conditions for our model to be valid we expect that soil textures other than sandy will not allow cyclic dynamics to occur. We expect this because an important condition to be met for cyclic dynamics is that plants grow and increase their biomass on hydrophilic wet soils, while they decrease biomass on hydrophobic dry soils. Whether this occurs is mainly controlled by the SWR threshold that separates the two soil states (see Figure 3B). Literature values suggest that this threshold moves toward higher soil moisture values for finer-textured soils (measured ranges for sandy soils: $1.75-4.75 \mathrm{vol} . \%$, loamy sand/sandy loam soils: 28 grav $\%$ and peaty clay/clayey peat soils: 34.6-38.2 vol\%; Dekker and Ritsema 1994; Doerr and Thomas 2000; Dekker and Ritsema 1996). At these higher values, plants may not be stressed enough to sufficiently reduce their biomass, thereby not allowing a shift from a hydrophobic dry to a hydrophilic wet state to occur (Figure 6IV-I), meaning that cyclic dynamics are hampered. A second reason that other soil textures may not allow cyclic vegetation dynamics to occur could be a weaker relationship between soil hydrophobic compound concentration and SWR. While we found a significant correlation (see Figure $3 \mathrm{~A}$ ) between total hydrophobic compound concentration and SWR, we are not aware of studies on undisturbed finer-textured soils that report significant correlations (Doerr and others 2005; DeBano 1991).

Climate change for the northwest European coastal dunes encompasses decreasing summer precipitation, increasing precipitation deficits in the growing season, a longer growing season, wetter winters, and rising temperatures (KNMI 2015; IPCC 2013). Our model suggests that an increase in drought severity in combination with SWR could result in shifts from vegetated to bare ecosystem states (see Figure 10). This finding is in line with extrapolations of a statistical model by Witte and others (2008) that indicate an increasing fraction of bare soil as precipitation deficit increases. Witte and others (2008) also hypothesize that, due to SWR, climate change may result in increased heterogeneity and enhanced patchiness, a hypothesis that we could not test with our model as it does not capture spatial processes. Besides changes in summer precipitation, vegetation dynamics may be affected by increasing winter precipitation and winter temperatures through enhanced decomposition rates of (hydrophobic) organic compounds (Davidson and Janssens 2006; Kirschbaum 1995; Laiho and others 2004). The resulting decrease in soil hydrophobic compound concentrations would lower the likelihood of cyclic dynamics to occur. However, this effect may be diminished the increased turnover of biomass caused by the extended growing season. 
Although the presented model captures our observations of SWR in Zuid-Kennermerland and the three key feedbacks (Figure 4) that potentially control the SWR driven vegetation dynamics on coastal sand dunes, it only partly captures the complexity of SWR on molecular scale and soil scale. The current model uses total hydrophobic compound concentration as a predictor for SWR of dry soils (Figure 3A and Eq. 3). However, depending on their origin (plant species/plant tissues), hydrophobic compounds differ in their composition and consequently in their effect on SWR (Mao and others 2014). Mao and others (2015) identified a set of hydrophobic compounds, so-called SWR predictors, that can well predict SWR. These SWR predictors have a known origin and can therefore also be used to assess the relative contribution of different species and plant tissues to SWR. Mao and others (2014) found that root-derived hydrophobic compounds (suberins) are more hydrophobic than those originating from leaf waxes (free lipids). This may result in different impacts of hydrophobic compounds on SWR along the soil profile as leaves contribute relatively more to the organic matter in topsoils than roots, whereas in subsoils virtually all organic matter is derived from roots (Mao and others 2014). Finally, the various hydrophobic compound groups also decompose at different rates (Weisberg 2007; Feng and others 2010; Spielvogel and others 2010). A future model could incorporate this complexity by considering different hydrophobic compound groups or SWR predictors and by separating topand subsoils and above and below-ground biomass. A drawback of such a comprehensive modeling approach would be that a qualitative analysis, as performed in our study, may not be possible, meaning that analysis would need to be done numerically. A second way our model can be extended is by including spatial processes such as surface runoff and preferential flow that commonly occur in water repellent soils. This may give insights in the role of SWR in the observed spatial heterogeneity and may be used to test the hypothesis of enhanced patchiness of vegetation resulting from climate change (Witte and others 2008). Such models could also incorporate the temporal distribution of precipitation events, which is thought to play a key role in spatially extended ecosystems (Siteur and others 2014) and is projected to change in the coming decades (Tebaldi and others 2006). Finally, the model could be extended to include fires. Fires are known to be an important source of SWR in many ecosystems and may not only directly affect vegetation dynamics, but also indirectly through SWR and other soil surface changes (Ravi and others 2009; Sankey and others 2012).

Our findings, and those of future model studies, provide a more thorough understanding of the inherent complexity of the dune ecosystem and thereby they aid in assessing effect of climate change and human activities on the dune ecosystem.

\section{ACKNOWLEDGMENTS}

This study was funded by the Complexity program of the Netherlands Organization for Scientific Research (NWO) and the Earth and Life Science and Research Council (ALW) with financial aid from NWO (Grant number 821.01.004). We would like to thank Aat Barendregt, Marcel C.G. van Maarseveen, and Chris Roosendaal for providing ThetaProbe Soil Moisture Sensors.

\section{OPEN ACCESS}

This article is distributed under the terms of the Creative Commons Attribution 4.0 International License (http://creativecommons.org/licenses/by/ 4.0/), which permits unrestricted use, distribution, and reproduction in any medium, provided you give appropriate credit to the original author(s) and the source, provide a link to the Creative Commons license, and indicate if changes were made.

\section{REFERENCES}

Aagaard T, Orford J, Murray AS. 2007. Environmental controls on coastal dune formation; Skallingen Spit Denmark. Geomorphology 83(1-2):29-47.

Adema EB, Grootjans AP. 2003. Possible positive-feedback mechanisms: Plants change abiotic soil parameters in wet calcareous dune slacks. Plant Ecol 167(1):141-9.

Arens, B., Geelen, L., Van der Hagen, H., and Slings, R. (2007). Duurzame verstuiving in de Hollandse duinen: kans, droom of nachtmerrie. Eindrapport Fase 1. Technical report, Arens Bureau voor Strand- en Duinonderzoek, Amsterdam.

Bisdom EBA, Dekker LW, Schoute JFT. 1993. Water repellency of sieve fractions from sandy soils and relationships with organic material and soil structure. Geoderma 56:105-18.

Davidson EA, Janssens IA. 2006. Temperature sensitivity of soil carbon decomposition and feedbacks to climate change. Nature 440(7081):165-73.

De Blas E, Almendros G, Sanz J. 2013. Molecular characterization of lipid fractions from extremely water-repellent pine and eucalyptus forest soils. Geoderma 206:75-84.

DeBano, L.F. (1991). The effect of fire on soil properties. In Harvey, A.C. and Neuenschwander, L.F., editors, Proceedings - Management and Productivity of Western-Montane Forest Soils, pages 151-156. USDA.

DeBano LF. 2000. The role of fire and soil heating on water repellency in wildland environments: a review. J Hydrol 232:195-206. 
Dekker, L.W. and Jungerius, P.D. (1990). Water repellency in the dunes with special reference to The Netherlands. In Dunes of the European coasts. Catena Supplement, number 18, pages 173-183.

Dekker LW, Ritsema CJ. 1994. How water moves in a water repellent sandy soil. 1. Potential Actual Water Repel 30(9):2507-17.

Dekker LW, Ritsema CJ. 1996. Variation in water content and wetting patterns in Dutch water repellent peaty clay and clayey peat soils. Catena 28:89-105.

Doerr SH, Llewellyn CT, Douglas P, Morley CP, Mainwaring KA, Haskins C, Johnsey L, Ritsema CJ, Stagnitti F, Allinson G, Ferreira AJD, Keizer JJ, Ziogas AK, Diamantis J. 2005. Extraction of compounds associated with water repellency in sandy soils of different origin. Aust J Soil Res 43(3):225-37.

Doerr SH, Shakesby RA, Walsh RPD. 2000. Soil water repellency: its causes, characteristics and hydro-geomorphological significance. Earth Sci Rev 51:33-65.

Doerr SH, Thomas AD. 2000. The role of soil moisture in controlling water repellency: new evidence from forest soils in Portugal. J Hydrol 232:134-47.

Everard M, Jones L, Watts B. 2010. Have we neglected the societal importance of sand dunes? An ecosystem services perspective. Aquat Conserv: Marine Freshw Ecosyst 20(4):476-87.

Feng X, Xu Y, Jaffé R, Schlesinger WH, Simpson MJ. 2010. Turnover rates of hydrolysable aliphatic lipids in Duke Forest soils determined by compound specific 13C isotopic analysis. Org Geochem 41(6):573-9.

Franco CMM, Clarke PJ, Tate ME, Oades JM. 2000. Hydrophobic properties and chemical characterisation of natural water repellent materials in Australian sands. J Hydrol 231-232:4758.

Franco CMM, Tate ME, Oades JM. 1995. Studies on non-wetting sands. 1. The role of intrinsic particulate organic-matter in the development of water-repellency in non-wetting sands. Aust J Soil Res 33(2):253.

Grootjans AP, Everts H, Bruin K, Fresco L. 2001. Restoration of wet dune slacks on the Dutch Wadden sea islands: Recolonization after large-scale sod cutting. Restor Ecol 9(2):137-46.

Home J. 2015. The influence of the microflora on the physical properties of soils. I. Effects associated with filamentous algae and fungi. Soil Res 2(1):111-22.

Horne D, McIntosh J. 2000. Hydrophobic compounds in sands in New Zealand-extraction, characterisation and proposed mechanisms for repellency expression. J Hydrol 232:35-46.

IPCC 2013. Climate Change 2013: The Physical Science Basis. Contribution of Working Group I to the Fifth Assessment Report of the Intergovernmental Panel on Climate Change. Technical report, Cambridge, United Kingdom and New York, USA.

Jensen, F. 1994. Dune management in Denmark: application of the Nature Protection Act of 1992. J Coast Res 10(2):263-9.

Kirschbaum MU. 1995. The temperature dependence of soil organic matter decomposition, and the effect of global warming on soil organic C storage. Soil Biol Biochem 27(6):753-60.

Klijn JA. 1990. Dune forming factors in a geological context. In: Bakker TW, Jongerius PD, Klijn JA, Eds. Dunes of the European coasts; geomorphology, hydrology, soils. Cremlingen: Catena Verlag. p 1-14.

KNMI (2014). KNMI'14: Climate Change scenarios for the 21 st Century-A Netherlands perspective. Technical report.
KNMI 2015. Daggegevens van het weer in Nederland. URL: www.knmi.nl. Accessed 1 July 2015.

Kooijman AM, Dopheide JCR, Sevink J, Takken I, Verstraten JM. 1998. Nutrient limitations and their implications on the effects of atmospheric deposition in coastal dunes; lime-poor and lime-rich sites in the Netherlands. J Ecol 86:511-26.

Kooijman AM, Van der Meulen F. 1996. Grazing as a control against 'grass-encroachment' in dry dune grasslands in the Netherlands. Landsc Urban Plann 34(3-4):323-33.

Laiho R, Laine J, Trettin CC, Finér L. 2004. Scots pine litter decomposition along drainage succession and soil nutrient gradients in peatland forests, and the effects of inter-annual weather variation. Soil Biol Biochem 36(7):1095-109.

Le Bagousse-Pinguet Y, Forey E, Touzard B, Michalet R. 2013. Disentangling the effects of water and nutrients for studying the outcome of plant interactions in sand dune ecosystems. J Veg Sci 24(2):375-83.

Mao J, Nierop KGJ, Rietkerk M, Dekker SC. 2015. Predicting soil water repellency using hydrophobic organic compounds and their vegetation origin. Soil 1(1):411-25.

Mao J, Nierop KGJ, Sinninghe Damsté JS, Dekker SC. 2014. Roots induce stronger soil water repellency than leaf waxes. Geoderma 232-234:328-40.

McGhie DA, Posner AM. 1980. Water repellence of a heavy textured Western Australian surface soil. Aust J Soil Res 18(3):309.

Peltzer DA, Wardle DA, Allison VJ, Baisden WT, Bardgett RD, Chadwick OA, Condron LM, Parfitt RL, Porder S, Richardson SJ, Turner BL, Vitousek PM, Walker J, Walker LR. 2010. Understanding ecosystem retrogression. Ecol Monogr 80(4):509-29.

Provoost S, Jones MLM, Edmondson SE. 2009. Changes in landscape and vegetation of coastal dunes in northwest Europe: a review. J Coast Conserv 15(1):207-26.

Ravi S, Wang L, White CS, Okin GS, Macko S, Collins Sl. 2009. Post-fire resource redistribution in desert grasslands: a possible negative feedback on land degradation. Ecosystems 12:434-44.

Remke E, Brouwer E, Kooijman A, Blindow I, Roelofs JGM. 2009. Low atmospheric nitrogen loads lead to grass encroachment in coastal dunes, but only on acid soils. Ecosystems 12:1173-88.

Rietkerk M, Van den Bosch F, Van de Koppel J. 1997. Sitespecific properties and irreversible vegetation changes in semiarid grazing systems. Oikos 80:241-52.

Ritsema CJ, Dekker LW, Hendrickx JMH, Hamminga W. 1993. Preferential flow mechanism in a water repperlent sandy soil. Water Resour Res 29(7):2183-93.

Sankey JB, Ravi S, Wallace CSA, Webb RH, Huxman TE. 2012. Quantifying soil surface change in degraded drylands: shrub encroachment and effects of fire and vegetation removal in a desert grassland. J Geophys Res 117:1-11.

Scholes RJ, Walker BH, An African savanna: synthesis of the nylsvley study, Siteur K, Eppinga MB, Karssenberg D, Baudena M, Bierkens MFP, Rietkerk M. 2014. How will increases in rainfall intensity affect semiarid ecosystems? Water Resour Res 50(7):5980-6001.

Spielvogel S, Prietzel J, Kögel-Knabner I. 2010. Lignin phenols and cutin-and suberin-derived aliphatic monomers as biomarkers for stand history, SOM source, and turnover. In 19th World Congress of Soil Science, Soil Solutions for a Changing World, number August, pp. 74-77, Brisbane, Australia

Tebaldi C, Hayhoe K, Arblaster JM, Meehl GA. 2006. Going to the Extremes. Clim Chang 79(3-4):185-211. 
Tilman D. 1982. Resource competition and community structure. Monographs in population biology, 17, Princeton, pp. 1-296.

van den Berg LJ, Tomassen HBM, Roelofs JGM, Bobbink R. 2005. Effects of nitrogen enrichment on coastal dune grassland: a mesocosm study. Environ Poll 138:77-85.

Van der Maarel E, Boot R, Van Dorp D, Rijntjes J. 1985. Vegetation succession on the dunes near Oostvoorne, The Netherlands; a comparison of the vegetation in 1959 and 1980. Vegetatio 187:137-87.

Van Der Meulen F, Bakker T, Houston J. 2004. The costs of our coasts: examples of dynamic dune management from Western Europe. Coast Dunes: Ecol Conserv 171:259-77.

Van Dorp D, Boot R, Van Der Maarel E. 1985. Vegetation succession on the dunes near Oostvoorne, The Netherlands, since 1934, interpreted from air photographs and vegetation maps. Vegetatio 136:123-36.

Van 't Woudt BD. 1959. Particle coatings affecting the wettability of soils. J Geophys Res 64(2):263.

Veer MAC. 1997. Nitrogen availability in relation to vegetationchanges resulting from grass encroachment in Dutch dry dunes. J Coast Conserv 3:41-8.

Veer MAC, Kooijman AM. 1997. Effects of grass-encroachment on vegetation and soil in Dutch dry dune grassland. Plant Soil 192(1):119-28.
Voortman BR, Bartholomeus RP, van der Zee SEATM, Bierkens MFP, Witte JPM. 2015. Quantifying energy and water fluxes in dry dune ecosystems of the Netherlands. Hydrol Earth Syst Sci 19(9):3787-805.

Weisberg M. 2007. Richard Levins' philosophy of science. Biol Philos 21(5):603-5.

Wessel AT. 1988. On using the effective contact angle and the water drop penetration time for classification of water repellency in dune soils. Earth Surf Process Landf 13(6):55561.

Witte JPM, Bartholomeus RP, Cirkel DG, Kamps PWTJ. 2008. Ecohydrologische gevolgen van klimaatverandering voor de kustduinen van Nederland. Technical report.

$\mathrm{Xu}$ L, Myneni RB, Chapin FSIII, Callaghan TV, Pinzon JE, Tucker CJ, Zhu Z, Bi J, Ciais P, Tømmervik H, Euskirchen ES, Forbes BC, Piao SL, Anderson BT, Ganguly S, Nemani RR, Goetz SJ, Beck PS, Bunn AAG, Cao C, Stroeve J. 2013. Temperature and vegetation seasonality diminishment over northern lands. Nat Clim Chang 3(3):581-6.

Zagwijn W. 1970. Vegetational history. In: Jelgersma S, de Jong J, Zagwijn W, Altena JVR, Eds. The coastal dunes of the western Netherlands; geology, vegetational history and archeology. chapter IV, Rijksdienst voor het oudheidkundig bodemonderzoek. pp 122-132. 